\title{
Progress Report on Pre-Test Calculations for the Large Block Test
}

Kenrick $\mathrm{H}$. Lee

January 1995

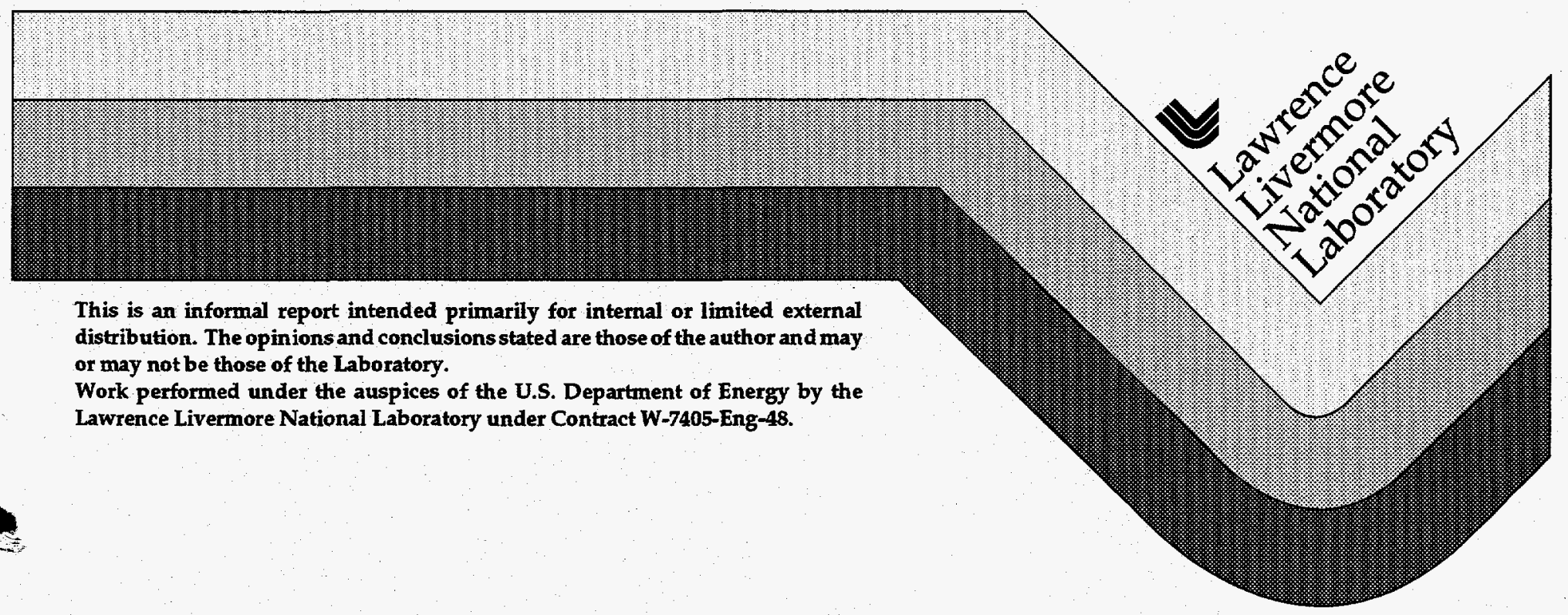

This is an informal report intended primarily for internal or limited external distribution. The opinions and conclusions stated are those of the author and may

Work performed under the auspices of the U.S. Department of Energy by the awrence Livermore National Laboratory under Contract W-7405-Eng-48. 


\section{DISCLAIMER}

This document was prepared as an account of work sponsored by an agency of the United States Government. Neither the United States Government nor the University of California nor any of their employees, makes any warranty, express or implied, or assumes any legal liability or responsibility for the accuracy, completeness, or usefulness of any information, apparatus, product, or process disclosed, or represents that its use would not infringe privately owned rights. Reference herein to any specific commercial product, process, or service by trade name, trademark, manufacturer, or otherwise, does not necessarily constitute or imply its endorsement, recommendation, or favoring by the United States Government or the University of California. The views and opinions of authors expressed herein do not necessarily state or reflect those of the United States Covernment or the University of Califomia, and shall not be used for advertising or product endorsement purposes.

This report has been reproduced directly from the best available copy.

Available to DOE and DOE contractors from the Office of Scientific and Technical Information P.O. Box 62, Oak Ridge, TN 37831

Prices available from (615) 576-8401, FTS 626-8401

Available to the public from the National Technical Information Service

U.S. Department of Commerce 5285 Port Royal Rd. Springfield, VA 22161 


\section{DISCLAIMER}

Portions of this document may be illegible in electronic image products. Images are produced from the best available original document. 


\title{
Progress Report on Pre-Test Calculations for the Large Block Test
}

\author{
Kenrick H. Lee
}

January 20, 1995 


\begin{abstract}
The U.S. Department of Energy's (DOE) Yucca Mountain Site Characterization Project (YMP) is investigating the suitability of the Topopah Spring tuff in the thick vadose zone at Yucca Mountain, Nevada, as a host rock for permanent disposal of high-level radioactive waste. As part of the YMP, a group of field tests, referred to as the Large Block Test (LBT), will be conducted on a large electrically heated block of Topopah Spring tuff, isolated at Fran Ridge, Nevada Test Site. The block, which will be $3 \times 3 \mathrm{~m}$ in horizontal dimensions and $4.5 \mathrm{~m}$ in height, will be heated by electrical heaters installed in 5 boreholes drilled in a horizontal plane $1.5 \mathrm{~m}$ above the base of the block. The goals of the LBT are to gain information on the coupled thermal-mechanical-hydrological-chemical processes that will be active in the near-field environment of a repository; to provide field data for testing and calibrating models; and to help in the development of measurement systems and techniques. In this progress report, we present results of ongoing numerical modeling calculations we are carrying out in support of the LBT design. We use an equivalent continuum model with an upper boundary temperature of $60^{\circ} \mathrm{C}$ to simulate the hydrothermal response of the block to heating over a one-year period. The total heating power in the model was started at $1500 \mathrm{~W}$ and was later reduced to maintain an approximately uniform temperature of $138-140^{\circ} \mathrm{C}$ along the heater plane. For a homogeneous bulk permeability case, the results show the formation of a distinct dry-out zone in and around the heater plane, and well-developed condensation zones above and below the heater plane. For the case of a heterogeneous permeability distribution, the condensation zone above the heater plane was not well developed. This difference in results between the two cases suggests that the water saturation changes might be sensitive to changes in bulk permeability distribution. Rock temperatures were almost unaffected by changes in the permeability distribution. The maximum heat flow rate through the top of the block was 480-500 W. Heat flow was dominated by conduction. No liquid flow through the top of the block was predicted.
\end{abstract}




\section{Introduction}

\subsection{Background}

The U.S. Department of Energy's (DOE) Yucca Mountain Site Characterization Project (YMP) is investigating the suitability of the Topopah Spring tuff in the thick vadose zone at Yucca Mountain, Nevada, as a host rock for permanent disposal of high-level radioactive waste. Because heatdriven fluxes of liquid water and water vapor in the near-field repository environment will affect waste package deterioration rates and the transport of radionuclides away from the packages, scientists at Lawrence Livermore National Laboratory (LLNL) and elsewhere are studying this hydrothermal flow behavior. The studies include numerical modeling (Buscheck and Nitao, 1993a, 1993b), and field and laboratory testing (Ramirez et al., 1991; Lin and Daily, 1989).

Heat generated from radioactive decay of the waste is expected to drive coupled thermal-mechanical-hydrological-chemical (TMHC) processes in the near-field repository environment. A group of field tests to be conducted on a large electrically heated block of Topopah Spring tuff, isolated at Fran Ridge, Nevada Test Site, will be used to gain information on these processes. The tests, collectively referred to as the Large Block Test (LBT), are described by Lin et al. (1994a). The LBT will also provide data for testing and calibration of models and will help in the development and evaluation of measurement systems and techniques.

\subsection{Purpose}

This progress report presents results of ongoing numerical modeling calculations we are carrying out in support of the LBT design. We are using the V-TOUGH code to to carry out these hydrothermal simulations, using the equivalent continuum approach to modeling fluid flow and heat transport through the highly fractured rock. 


\subsection{Scope}

The general design of the large block will first be presented, followed by a brief description of the code. Grid design, input data selection, and boundary and initial conditions will then be given. Next, modeling results will be presented for a homogeneous block having the dominant bulk permeability measured by single-borehole air injection along a vertical borehole through the center of the block. These results will be compared with results obtained using the measured heterogeneous permeability distribution. The effect of changes in the upper boundary temperature will also be examined. This is followed by a summary and conclusions section, and a list of items to be addressed in future simulations.

\section{Description of the Block}

The rock surrounding the block was excavated using mechanical excavation and cutting with a rock saw. The isolated block has four vertical free faces and a horizontal upper surface. The horizontal dimensions are $3 \times 3 \mathrm{~m}$ and the height is $4.5 \mathrm{~m}$. The base of the block remains attached to the underlying rock. Five parallel heater emplacement boreholes will be drilled horizontally into one block face, normal to the face, in a plane $1.5 \mathrm{~m}$ above the base of the block. Figure 1 shows a front view of the block, indicating the locations of the heater emplacement boreholes. The spacing between the boreholes is $60 \mathrm{~cm}$, and the distance of each end borehole from the neighboring vertical wall is $30 \mathrm{~cm}$. The length of each borehole will be approximately $2.70 \mathrm{~m}$. Each borehole will house an electrical heater capable of delivering at least $300 \mathrm{~W}$, giving a minimum power capacity of $1500 \mathrm{~W}$ for the 5 boreholes. Heat will be delivered uniformly along the length of each borehole. A number of additional boreholes will carry instrumentation to monitor the hydrothermal, mechanical, and chemical response of the block to thermal and mechanical loading. A detailed description of the block design and excavation is given by Lin et al. (1994a). 


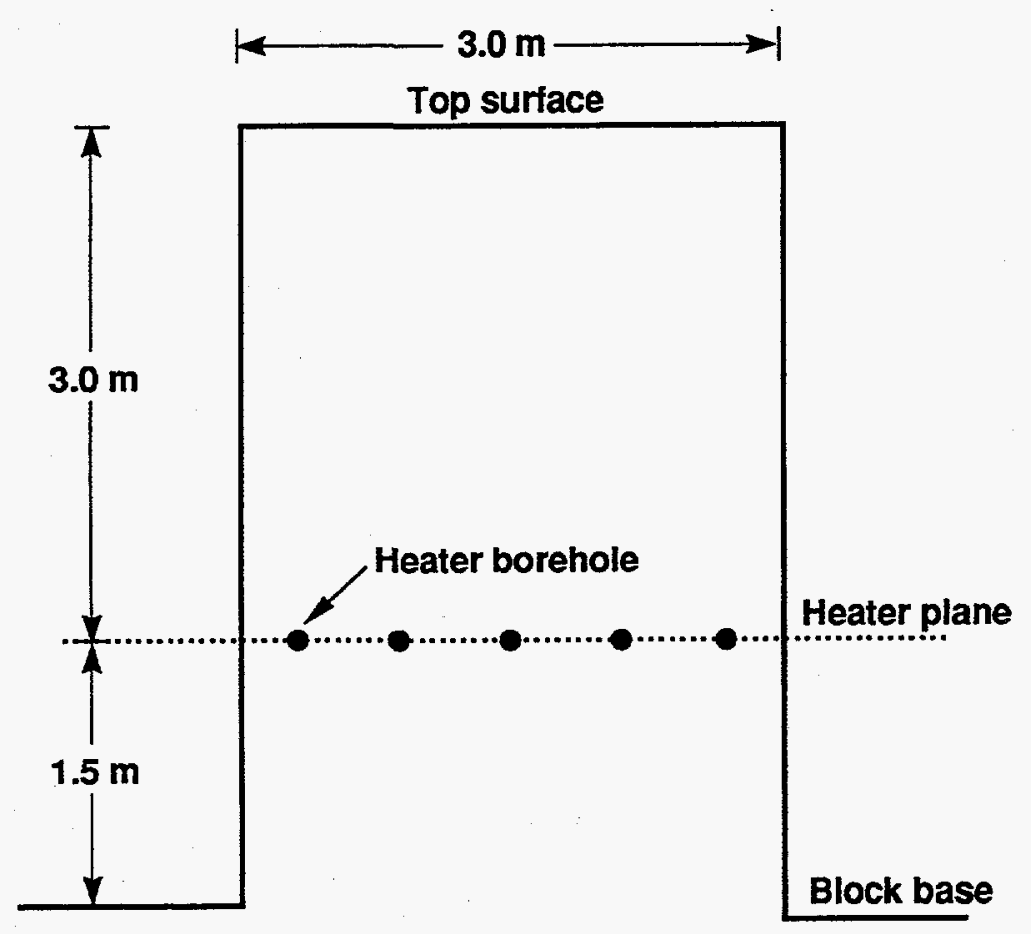

Figure 1. Front view of block showing location of heater boreholes.

\section{V-TOUGH Code}

Hydrothermal calculations were done using V-TOUGH (Nitao, 1989), LLNL's enhanced version of the TOUGH code developed by Pruess (1987) at Lawrence Berkeley Laboratory. V-TOUGH stands for Vectorized Transport of Unsaturated Groundwater and Heat. V-TOUGH is frequently used to simulate the transport of water, air, and heat in a high-level nuclear waste repository (e.g. Buscheck and Nitao, 1993a, 1993b).

In these large block simulations, we use the V-TOUGH implementation of equivalent-continuum analysis to model fluid flow through the fractured rock. The equivalent continuum approximation for modeling fracturematrix flow is described by Nitao (1988). With this technique, suction pressures for the matrix, given as a function of matrix saturation, and suction pressures for the fracture, given as a function of fracture saturation, are combined to give suctions as a function of bulk saturation. It is assumed that the pressures in the matrix and fracture are equal. The relative permeability of the equivalent continuum is a linear combination of the relative 
permeabilities of the fracture and matrix.

\section{Grid Design and Input Data}

Since heat and fluid flow will be symmetrical about a vertical plane drawn through the axis of the block and parallel to the heater emplacement boreholes, it is necessary to model only one half of the block. It is assumed that heat is delivered uniformly along the length of each borehole, and that the power levels in the boreholes are identical, so that a two-dimensional analysis is appropriate.

The grid is designed to give higher resolution close to and above the heater plane, and decreased resolution at greater distances beneath the heater plane. Figure 2 shows the grid design in and near the block. Larger grid sizes at greater depths beneath the block and at greater distances to the right are not shown. The modeled domain is 25 nodes in the $\mathrm{x}$-direction by 37 nodes in the $z$-direction. The grid extends a distance of $33 \mathrm{~m}$ in the $\mathrm{x}$-direction and a depth of $45 \mathrm{~m}$ in the z-direction. The third dimension, into the paper, is a single node thick, extending the full 3-m thickness of the block. Mesh size varies from $5 \mathrm{~cm}$ in the heater plane to $12 \mathrm{~m}$ at the right and lower boundaries. Null blocks fill the rectangular void between $\mathrm{x}$-values of 1.5 and $33 \mathrm{~m}$, and $\mathrm{z}$-values of 0 and $4.5 \mathrm{~m}$.

The upper surface of the block is held at a constant gas-phase pressure of $82.7 \mathrm{kPa}(12 \mathrm{psia})$ and a constant temperature of $60^{\circ} \mathrm{C}$. The upper boundary pressure of $82.7 \mathrm{kPa}$ represents average barometric pressure at the site, and the temperature of $60^{\circ} \mathrm{C}$ was selected to give a realistic temperature gradient above the heater plane. This upper boundary condition permits fluid and heat flow through the top of the block. Runs were also made with the upper boundary temperature set at $20^{\circ} \mathrm{C}$ and $80^{\circ} \mathrm{C}$ for comparison with the $60^{\circ} \mathrm{C}$ case. The left boundary, which represents a vertical symmetry plane through the center of the block parallel to the heater boreholes, is modeled as an adiabatic and impermeable boundary. The right boundary above the block base is also treated as adiabatic and impermeable. The lower boundary, and the right boundary below the block base, are isothermal and impermeable, so that pressure changes can occur to allow initial pneumatostatic equilibrium conditions for runs. 


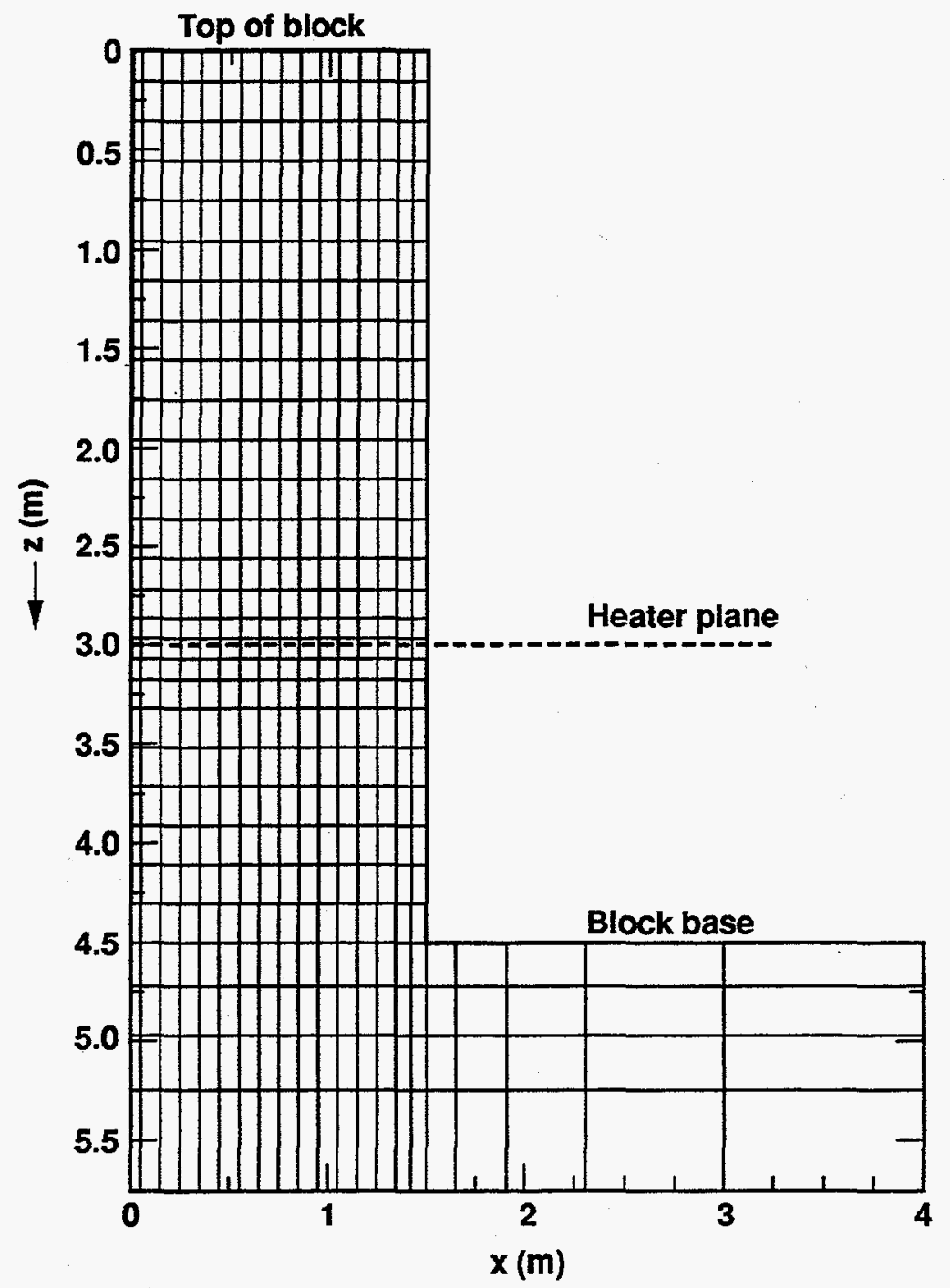

Figure 2. Grid design for half symmetry block section modeled. Only discretization inside and close to the block is shown. Larger grid sizes at greater distances away from the block are not shown. 
Table 1. Primary thermal and hydrologic parameters.

\begin{tabular}{|c|c|}
\hline Specific heat & $840 \mathrm{~J} / \mathrm{kg} .{ }^{\circ} \mathrm{C}$ (YMP RIB, 1990) \\
\hline Thermal conductivity (wet) & $2.10 \mathrm{~W} / \mathrm{m} .{ }^{\circ} \mathrm{C}(\mathrm{YMP} \mathrm{RIB}, 1990)$ \\
\hline Matrix porosity & $11 \%$ (YMP RIB, 1990) \\
\hline Bulk permeability & 4.67 mdarcy (Lin et al. 1994b) \\
\hline
\end{tabular}

All runs are made from an initial temperature of $20^{\circ} \mathrm{C}$ and initial water saturation of $50 \%$. A preliminary run was made, with heat turned off, to attain pneumatostatic equilibrium gas phase pressures which were used as initial gas pressures for subsequent runs. The liquid saturation profile did not change substantially during this preliminary run.

Some of the primary thermal and hydrologic parameters used are listed in Table 1. With the exception of bulk permeability, data were obtained from the YMP Reference Information Base (1990). Figure 3 shows the permeability-depth profile used in the heterogeneous model. The profile was obtained by single-borehole air injection into packed-off sections of a vertical borehole through the center of the block (Lin et al. 1994b). The permeability varies from $1.1 \times 10^{-4}$ darcy at a depth of $1.4 \mathrm{~m}$ below the top to 7.56 darcy at a depth of 3.4-3.8 m below the top. Most of the results presented were obtained assuming a homogeneous bulk permeability of 4.67 mdarcy, which is taken to be the dominant bulk permeability shown in Figure 3.

\section{Variable-Power Heating}

We first examine the case where the top surface temperature of the block is fixed at $60^{\circ} \mathrm{C}$, and the heating power is varied to attain a maximum heater borehole temperature of approximately $138-140^{\circ} \mathrm{C}$. Based on the results of preliminary runs, this heater borehole temperature range was thought to be adequate for the development of distinct dry-out and condensation zones 


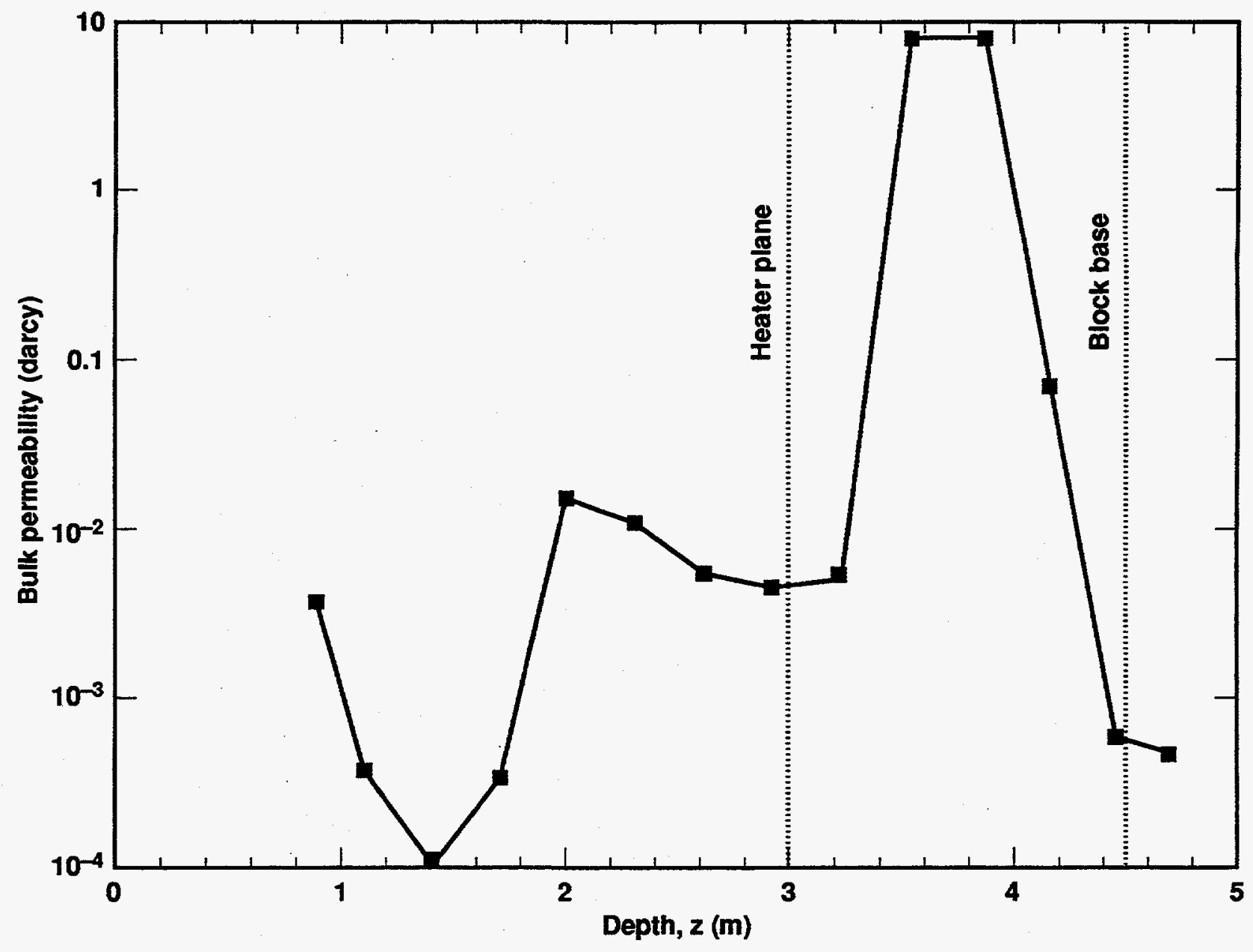

Figure 3. Bulk permeability profile in block, measured by single-borehole air injection (Lin et al., 1994b). 
within the block. The dry-out zone is defined here as the zone having a liquid saturation of less than half of the initial value. With an initial liquid saturation of $50 \%$, any point having a liquid saturation less than $25 \%$ is within the dry-out zone. The temperature history within a heater borehole and the total heating power history are shown in Figure 4. With power initially at $1500 \mathrm{~W}$, the temperature rises steadily until the first power reduction is made after 75 days.

\subsection{Temperature and Liquid Saturation}

The distribution of block temperatures after one year of heating is shown in Figure 5. The isotherms indicate essentially one-dimensional heat flow, with the exception of the area of the heater plane, and areas close to and below the block base. Temperatures range from a minimum of the prescribed $60^{\circ} \mathrm{C}$ at the upper boundary to a maximum of $140^{\circ} \mathrm{C}$ at the heater plane. At this stage of heating, the temperature gradients both above and below the heater plane are fairly uniform, suggesting that the heat flow is approaching steady-state conditions.

The one-year temperature and liquid saturation profiles down the center of the block (i.e., along $\mathrm{x}=0$ ) are shown in Figure 6. The liquid saturations, like the temperatures, are nearly one-dimensional above the base of the block. Therefore, the liquid saturation profile shown in Figure 6 is approximately the same for any $\mathrm{x}$-value across the block. Distinct dry-out and condensation zones are observed. The dry-out zone is about $2.6 \mathrm{~m}$ thick, and extends above and below the heater plane. Distinct condensation zones at up to full liquid saturation occur above and below the heater plane, centered at about $1.0 \mathrm{~m}$ and $4.7 \mathrm{~m}$ below the top of the block. Some drying occurs at the top of the block because of the relatively high $60^{\circ} \mathrm{C}$ upper boundary temperature. The temperature profile is nearly linear above the heater plane, with a slight increase in gradient about $25 \mathrm{~cm}$ above the plane.

The one-year temperature and liquid saturation profiles for the heterogeneous permeability case, using heater powers and initial and boundary conditions identical to the homogeneous case, is shown in Figure 7 . In contrast to the homogeneous case, a well-developed condensation zone above the heater plane is not observed. A distinct dry-out zone is seen, and a 


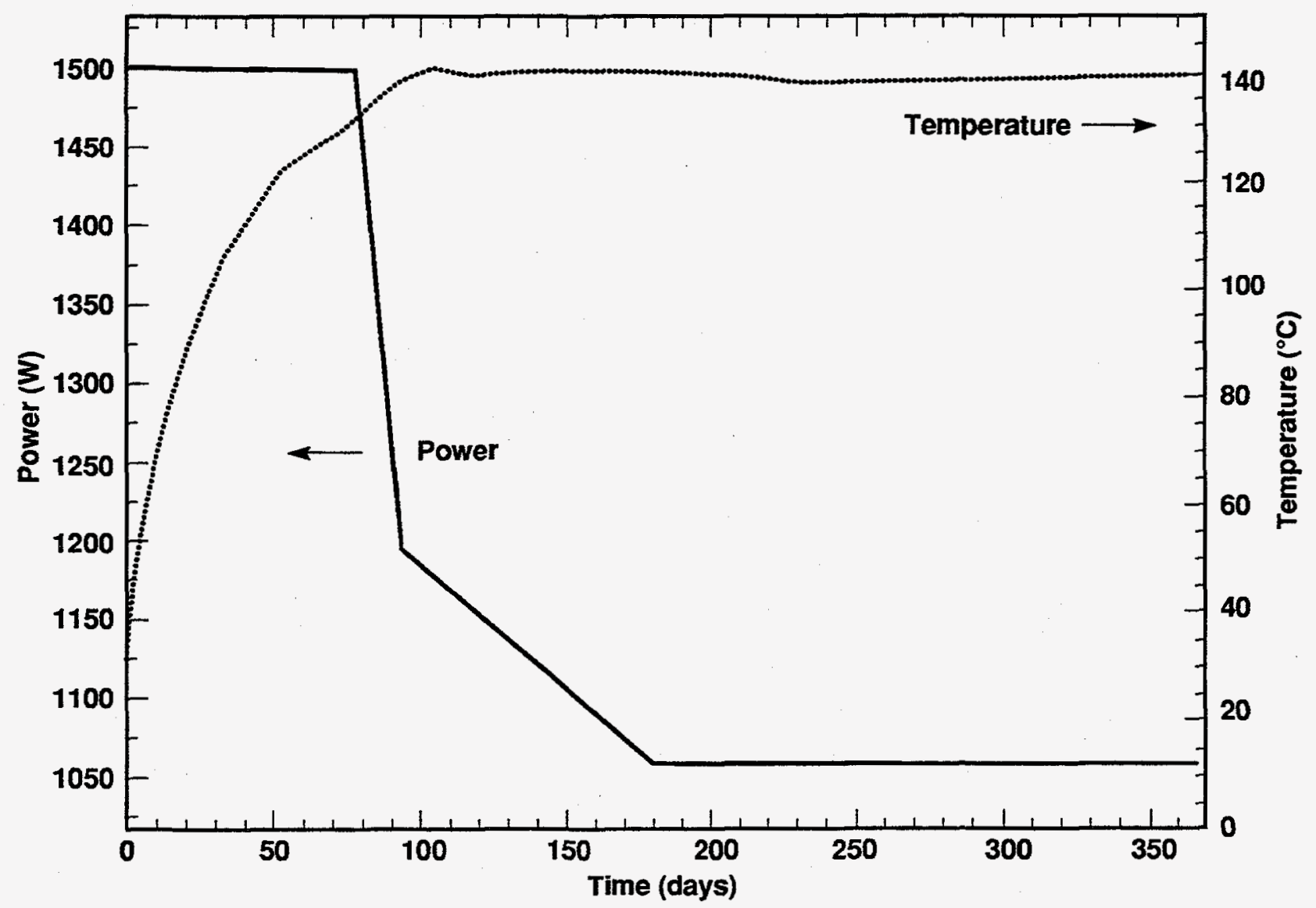

Figure 4. Total heating power and borehole temperature histories. 


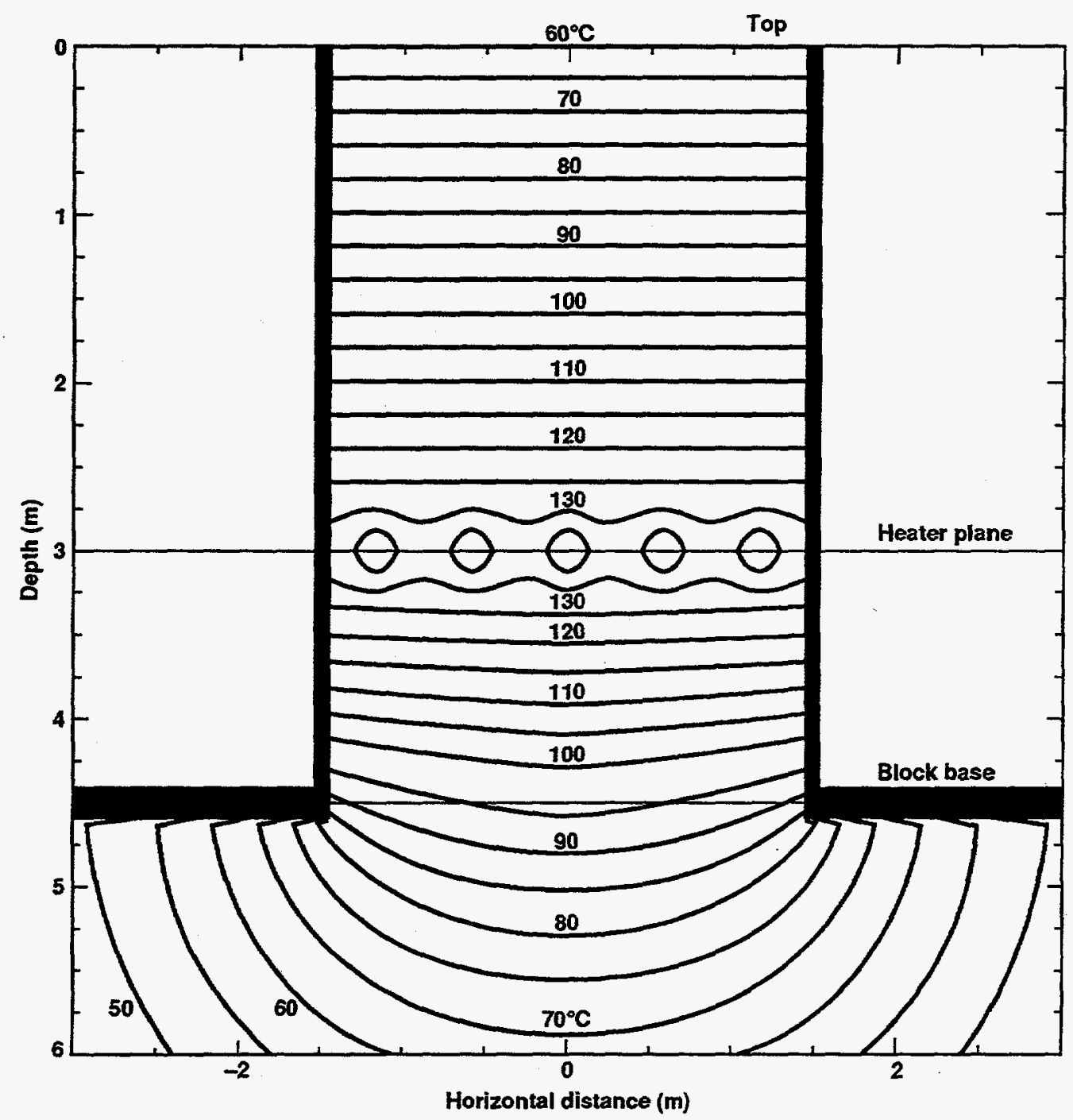

Figure 5. Block temperatures $\left({ }^{\circ} \mathrm{C}\right)$ after 365 days of heating. Homogeneous permeability and variable heater power. 


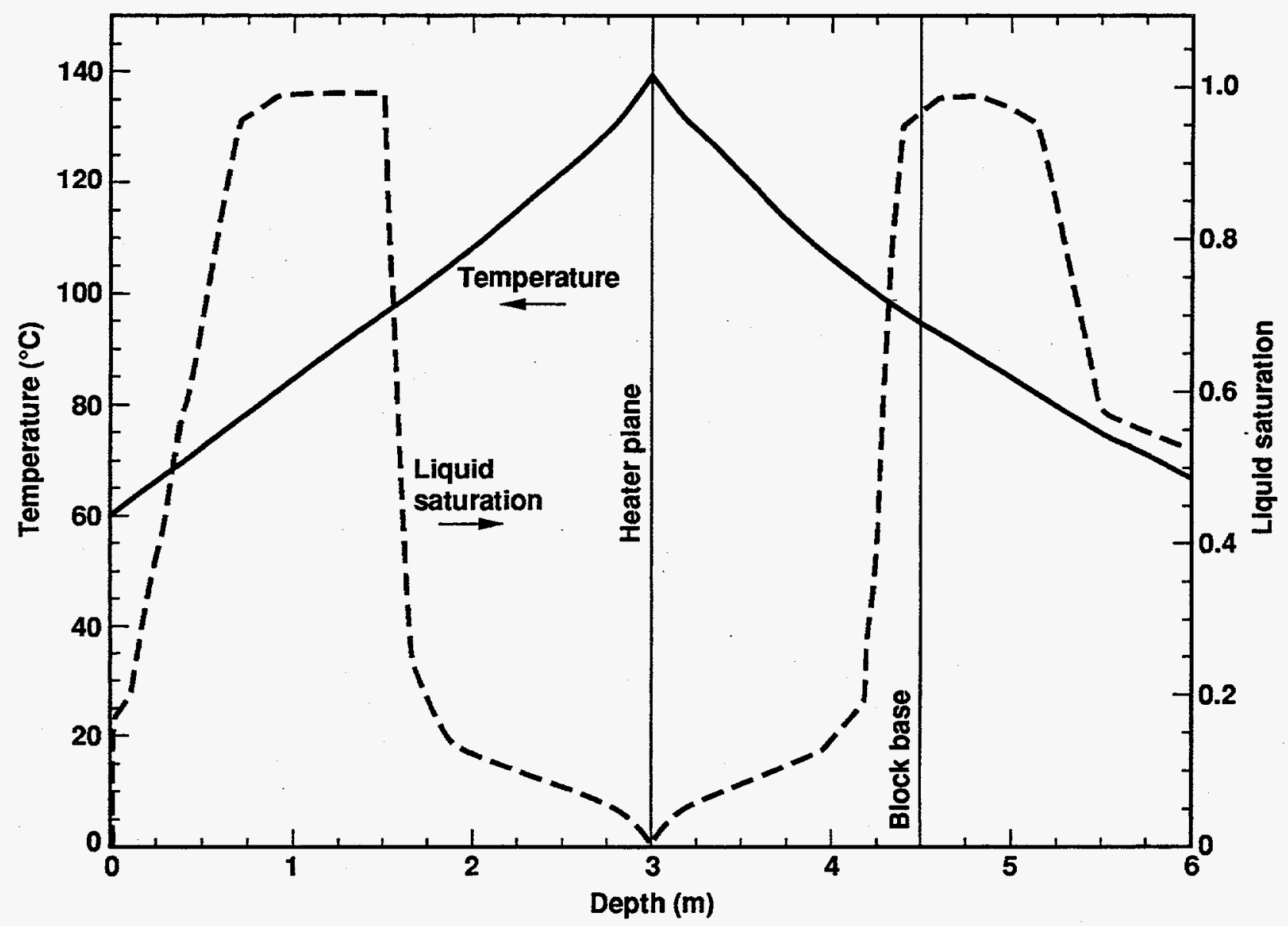

Figure 6. Temperature and liquid saturation profiles after 365 days of heating. Homogeneous permeability and variable heater power. 


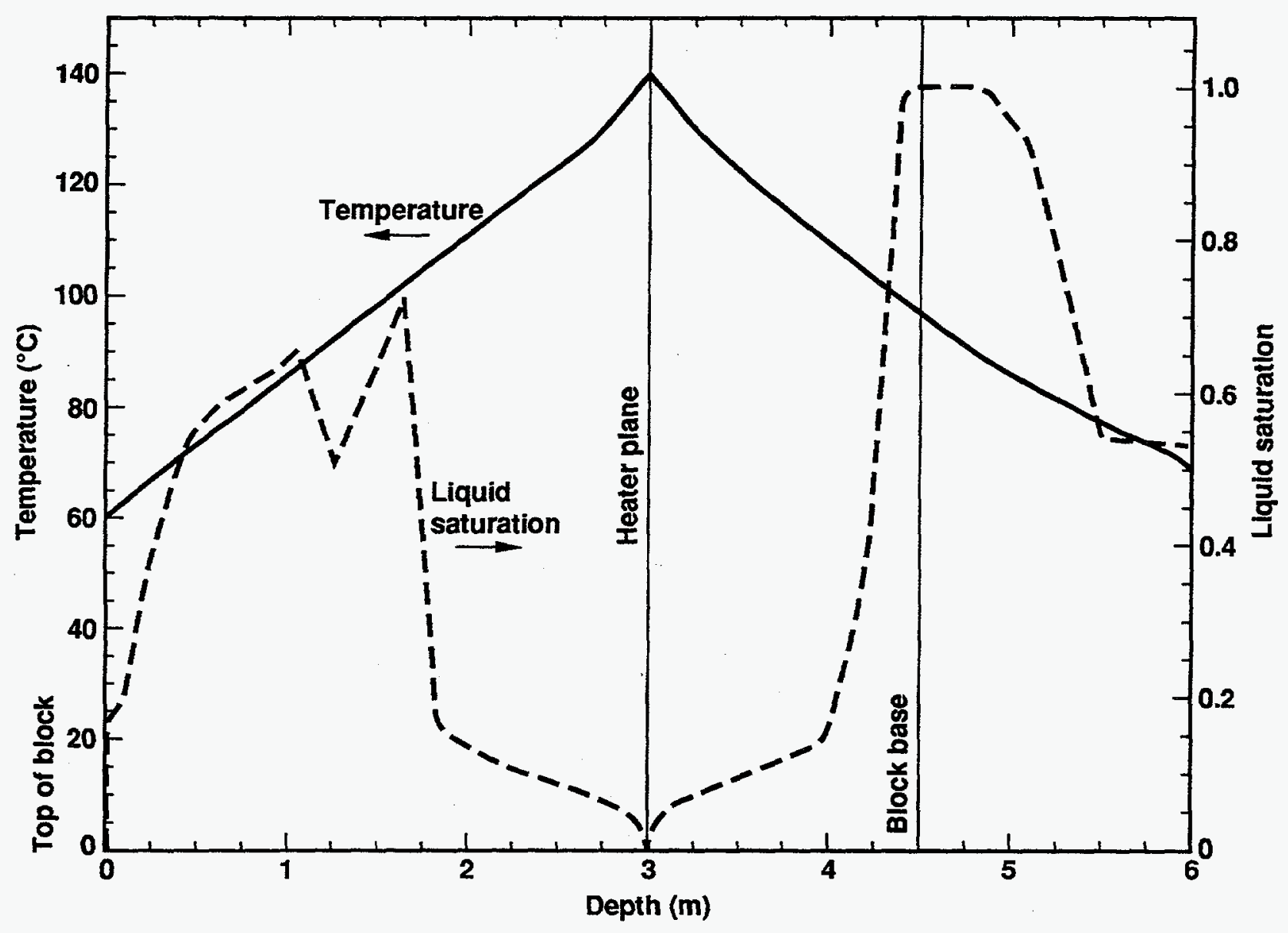

Figure 7. Temperature and liquid saturation profiles after 365 days of heating. Heterogeneous permeability and variable heater power. 
well developed condensation zone is formed only below the heater plane. There is clearly a net loss of liquid above the heater plane. There was no liquid flux through the top of the block, and the vapor losses (about $8 \mathrm{~kg}$ over one year) are insufficient to explain the discrepancy. Lower resistance to flow caused by substantially higher permeability below the heater plane apparently caused more downward water movement, limiting the size of the condensation zone above the heater plane. The temperature profile is almost identical to the profile for the homogeneous permeability.

It should be noted that the permeability was measured by air injection into packed-off sections of a single vertical borehole down the center of the block. The bulk permeability measured for a depth interval was assumed to be uniform for that interval. No consideration was given to fracture orientation or geometry. Preliminary results from fracture mapping show subvertical and horizontal fracture systems. More reliable block permeability characterization would require air injection measurements in additional boreholes, and even cross-hole measurements. In any case, comparison of the homogeneous and heterogeneous cases does suggest that the liquid saturation changes may be sensitive to the bulk permeability distribution in the block, but that temperature changes are insensitive to bulk permeability.

Figure 8 shows the one-year gas pressure profile down the center of the block for homogeneous and heterogeneous bulk permeabilities. Peak gas-phase pressure for the homogeneous case was only $97 \mathrm{kPa}$ (14 psia), compared with the higher value of $157 \mathrm{kPa}$ (23 psia) for the heterogeneous case. The higher pressure is caused by additional confinement of water vapor by layers of bulk permeability substantially lower than the homogeneous permeability used.

\subsection{Heat and Fluid Fluxes through Top of Block}

The total and conductive heat flow rate histories through the top of the block are plotted in Figure 9. Heat transfer through the top of the block is clearly dominated by conduction. Convection apparently plays a minor role in heat movement through the block. The heat flow rate through the top of the block increases over the first 80 days, then levels off at a value of $480-500 \mathrm{~W}$. Heat flow through the top surface is into the block for the first 30 days because the upper boundary temperature of $60^{\circ} \mathrm{C}$ is higher than 


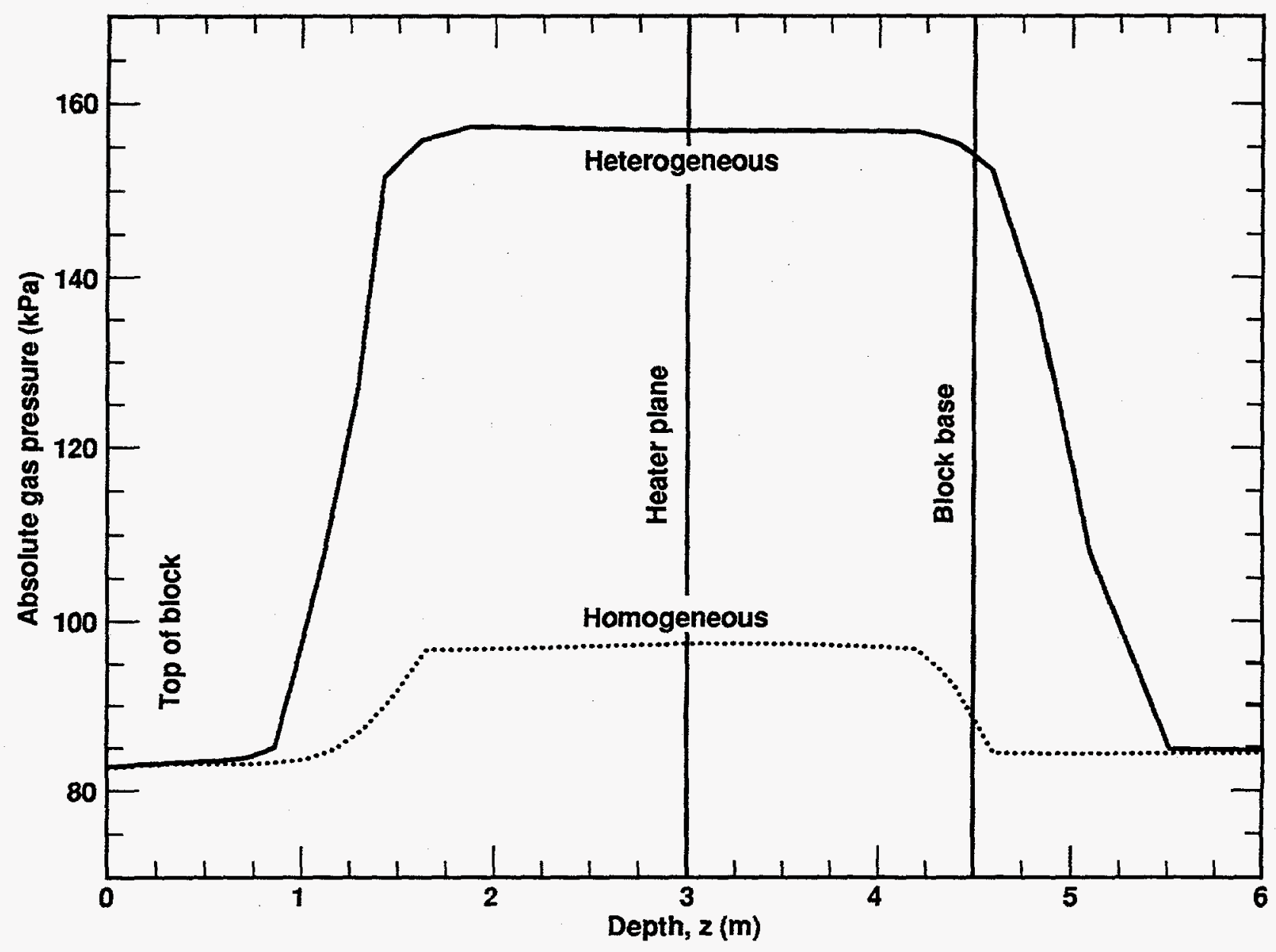

Figure 8. Absolute pressure profile of gas phase for homogeneous and heterogeneous block permeabilities, after 365 days of heating. Variable heater power. 


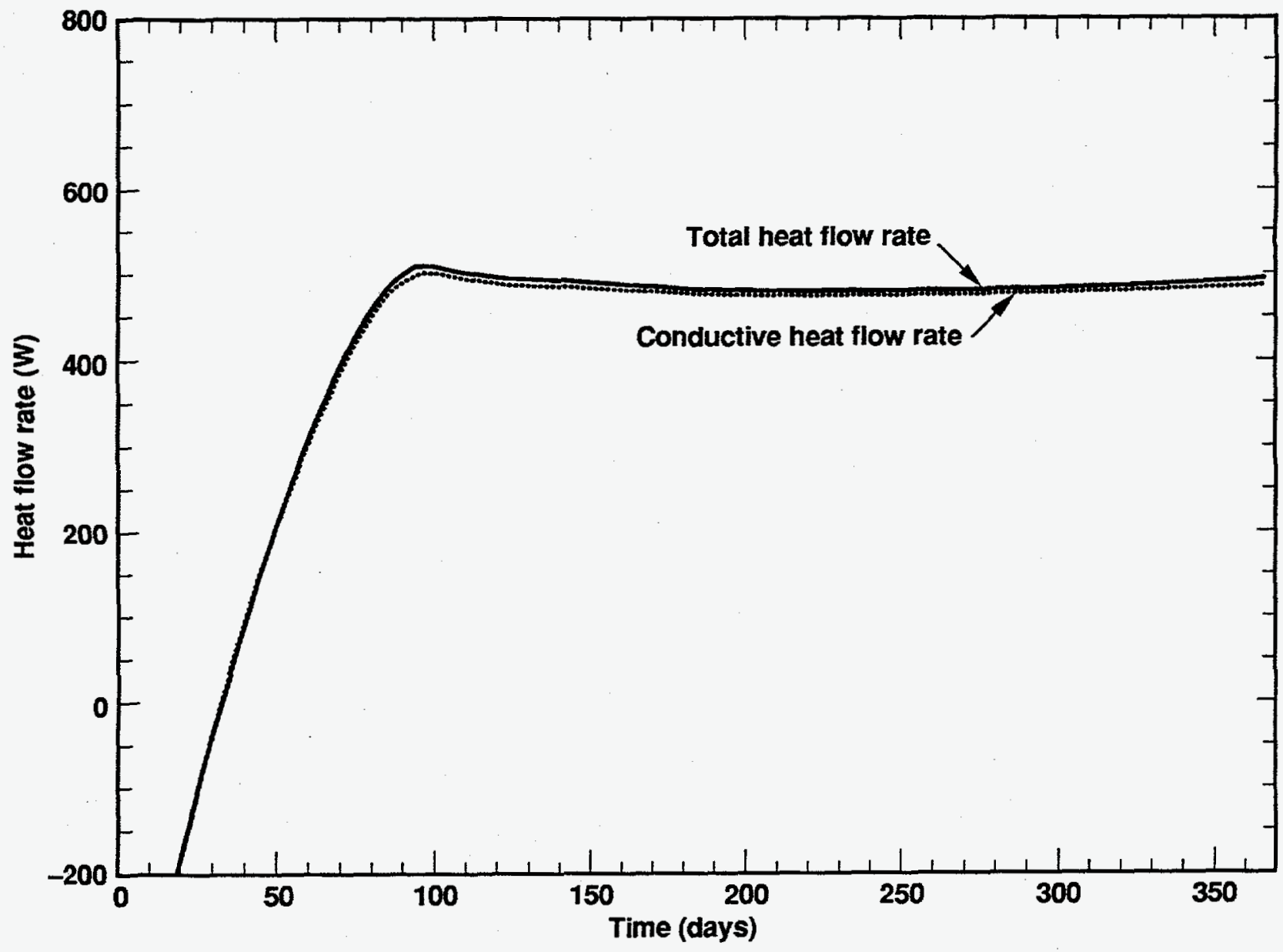

Figure 9. Total and conductive heat flow rate histories through top of block. Homogeneous permeability and variable heater power. 
the uniform initial block temperature of $20^{\circ} \mathrm{C}$.

The gas-phase flow rate history through the top of the block is shown in Figure 10. The peak flow rate occurs at 80 days and is approximately 2.4 $\times 10^{-6} \mathrm{~kg} / \mathrm{s}$. After 365 days of heating, the flow rate appears to be leveling off at about $1.9 \times 10^{-6} \mathrm{~kg} / \mathrm{s}$. At a temperature of $60^{\circ} \mathrm{C}$, the saturated mass fraction of water vapor in the gas phase passing through the top of the block is about 0.13 . For an average gas flux of about $2.0 \times 10^{-6} \mathrm{~kg} / \mathrm{s}$ over one year, the total mass of water vapor lost through the top of the block is about $8 \mathrm{~kg}$.

There was no liquid flux through the top of the block during the first year of heating.

\section{Constant-Power Heating}

We made three additional simulation runs to investigate the effects of the upper boundary temperature on the liquid saturation and temperature profiles. For these runs, we used the heterogeneous rock permeability distribution shown in Figure 3, and the total heating power was held constant at $1500 \mathrm{~W}$.

Figure 11 shows temperature and liquid saturation profiles along the vertical axis of the block at 100 days, for upper boundary temperatures of $20^{\circ} \mathrm{C}, 60^{\circ} \mathrm{C}$, and $80^{\circ} \mathrm{C}$. As with the variable-power run for the heterogeneous case described earlier, the condensation zone above the heater plane is not well developed, but a well-developed condensation zone is formed below the heater plane. The width of the dry-out zone increases with the upper boundary temperature, probably because of additional thermal energy put into the system to maintain the higher upper boundary temperature. The poorly developed condensation zone above the heaters is also pushed higher as the upper boundary temperature increases. The thickness of the condensation zone below the heater plane increases at higher upper boundary temperatures. 


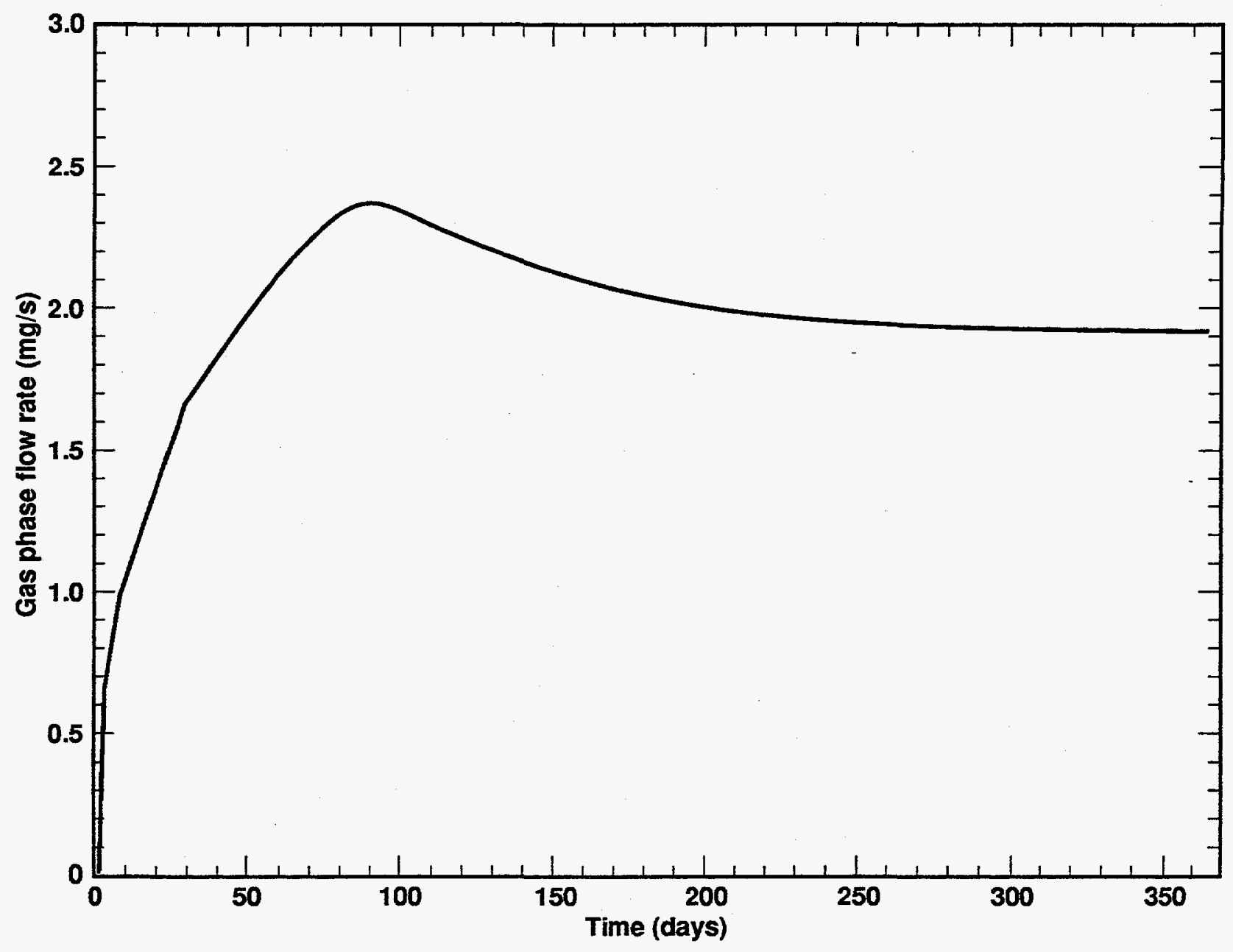

Figure 10. Gas phase flow rate history through top of block. Homogeneous permeability and variable heater power. 

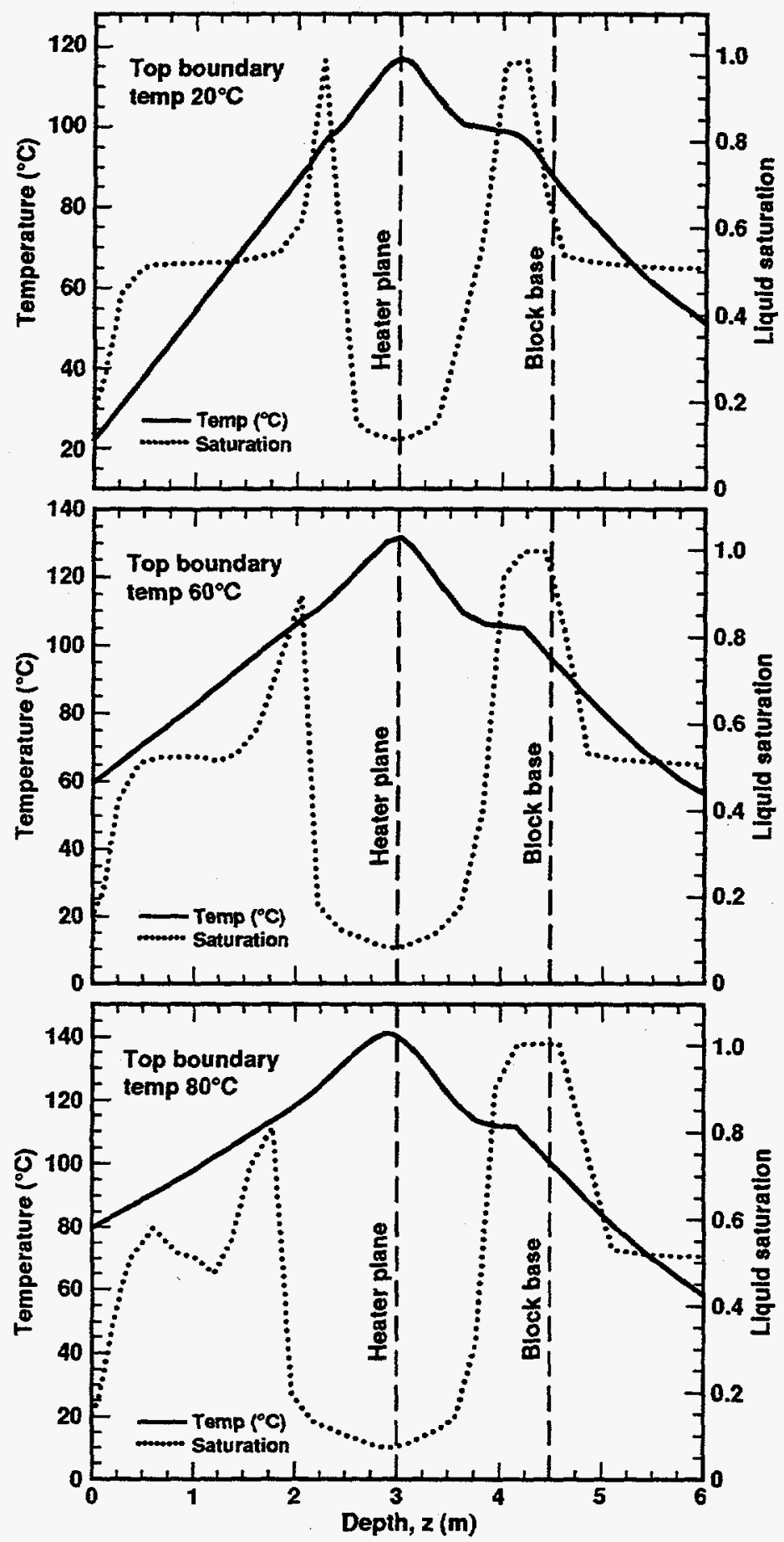

Figure 11. Temperature and liquid saturation profiles for upper boundary temperatures of $20^{\circ} \mathrm{C}, 60^{\circ} \mathrm{C}$, and $80^{\circ} \mathrm{C}$, after 100 days of heating. Heterogeneous permeability and uniform heating at $1500 \mathrm{~W}$. 


\section{Summary and Conclusions}

In this progress report we presented results of ongoing numerical modeling calculations we are conducting in support of the LBT design. We used an equivalent-continuum analysis with bulk permeability obtained from singlehole air injection measurements along a vertical borehole through the center of the block. Results were presented for a $60^{\circ} \mathrm{C}$ upper boundary temperature, assuming a homogeneous bulk permeability of 4.67 mdarcy. For these homogeneous runs, the total heating power was started at $1500 \mathrm{~W}$, and was later cut back to maintain an approximately uniform temperature of 138$140^{\circ} \mathrm{C}$ along the heater plane. The results for the homogeneous case were compared with results obtained using the measured heterogeneous permeability distribution. The effect of the upper boundary temperature on the liquid saturation and temperature profiles was also addressed.

For the homogeneous-permeability case, we observed a distinct dryout zone in and around the heater plane, and well-developed condensation zones above and below the heater plane. The dry-out zone is defined here as the zone having a liquid saturation of less than half of the initial value. For the heterogeneous-permeability case, the condensation zone above the heater plane was not well developed. This difference in results between the two cases suggests that the water saturation changes might be sensitive to changes in bulk permeability distribution. Higher gas pressures were generated in the block for heterogeneous permeability, probably because of confinement of gases by rock sections of relatively low bulk permeability. Rock temperatures were almost unaffected by changes in the permeability distribution. For the homogeneous case, the maximum heat flow rate through the top of the block was 480-500 W. Heat flow was dominated by conduction. The maximum gas-phase flow rate through the top of the block was $2.4 \times 10^{-6} \mathrm{~kg} / \mathrm{s}$; the water vapor mass fraction was about 0.13 . The total mass of water vapor lost through the top of the block was $8 \mathrm{~kg}$. No liquid flow through the top of the block was observed in any of the calculations. 


\section{Future Work}

Future calculations will address effects of the following:

- Fracture orientation.

- Water vapor diffusion enhancement under thermal gradients.

- Lower heater-zone temperatures. 


\section{References}

Buscheck, T.A., and J.J. Nitao, "The Analysis of Repository-Heat-Driven Hydrothermal Flow at Yucca Mountain," American Nuclear Society, Proceedings, Fourth International High-Level Radioactive Waste Management Conference, Las Vegas, NV, April 1993. Also, UCRL-JC-112444, Lawrence Livermore National Laboratory, Livermore, CA (1993a). (NNA.930315.0009)

Buscheck, T.A., and J.J. Nitao, "Repository-Heat-Driven Hydrothermal Flow at Yucca Mountain, Part I: Modeling and Analysis," Nuclear Technology, Vol. 104, No. 3, pp. 418-448 (1993b). (NNA.940427.0095)

Lin W., and W. Daily, "Laboratory Study of Fracture Healing in Topopah Spring Tuff - Implications for Near Field Hydrology," Proceedings of the Topical Meeting on Nuclear Waste Isolation in the Unsaturated Zone, Focus '89, American Nuclear Society, La Grange Park, IL (1989). (NNA.900711.0241).

Lin, W., D.G. Wilder, J.A. Blink, S.C. Blair, T.A. Buscheck, D.A. Chesnut, W.E. Glassley, K. Lee, and J.J. Roberts, "The Testing of ThermalMechanical-Hydrological-Chemical Processes Using a Large Block," UCRLJC-114776, Lawrence Livermore National Laboratory, Livermore, CA (1994a). (RA)

Lin, W., D.G. Wilder, J.A. Blink, S.C. Blair, T.A. Buscheck, R.S. Glass, W.E. Glassley, K. Lee, R.D. McCright, M.W. Owens, and J.J. Roberts, "A Large Block Heater Test for High Level Nuclear Waste Management," UCRL-JC-116431, Lawrence Livermore National Laboratory, Livermore, CA (1994b). (RA)

Nitao, J.J., "Numerical Modeling of the Thermal and Hydrological Environment around a Nuclear Waste Package Using the Equivalent Continuum Approximation: Horizontal Emplacement," Lawrence Livermore National Laboratory, Livermore, CA, UCID-21444 (1988). (NNA.890317.0021)

Nitao, J.J., "V-TOUGH - An Enhanced Version of the TOUGH Code for the Thermal and Hydrologic Simulation of Large-Scale Problems in Nuclear 
Waste Isolation," UCID-21954, Lawrence Livermore National Laboratory, Livermore, CA (1989). (RA)

Preuss, K., "TOUGH User's Guide," NUREG/CR-4645, Nuclear Regulatory Commission (1987). (NNA.930312.0190)

Ramirez, A.L., T.A. Buscheck, R. Carlson, W. Daily, K. Lee, W. Lin, N. Mao, T.S. Ueng, H. Wang, and D. Watwood, "Prototype Engineered Barrier System Field Test (PEBSFT), Final Report," UCRL-ID-106159, Lawrence Livermore National Laboratory, Livermore, CA (1991). (RA)

"Yucca Mountain Project Reference Information Base," YMP/CC-0002 (Version 04.002), Nevada Operations Office, U.S. Department of Energy (1990). (NNA.910129.0066) 
The following number is for Office of Civilian Radioactive Waste Management Records Management purposes only and should not be used when ordering this document:

Accession Number:

MOL.19950314.0178 